\title{
Silagens de capim elefante (pennisetum purpureum schum) com inclusão do resíduo de fécula de mandioca
}

\section{Elephant Grass Silages (pennisetum Purpureum Schum.) With Inclusion Of Cassava Starch By-products}

Ândresson Carvalho da Silva ${ }^{1}$, Andréa Krystina Vinente Guimarães ${ }^{2 *}$, Eloise Marcele Maia $\mathrm{Rego}^{2}$, Aline Dalmara Maia de Sousa ${ }^{2}$, Ronaldo Francisco Lima ${ }^{2}$, Ione Iolanda dos Santos ${ }^{2}$

\section{RESUMO}

Objetivou-se avaliar as silagens de capim elefante (P. purpureum schum) com a inclusão de resíduo de fecularia. O delineamento foi o inteiramente casualizado com cinco níveis de inclusão de resíduo na matéria natural $(0 \%, 10 \%, 20 \%, 30 \%$ e $40 \%)$ com quatro repetições. Os silos foram abertos após 49 dias de fermentação. A estabilidade foi prolongada com o aumento dos níveis do resíduo. A adição do resíduo de fecularia reduziu as perdas por gases. As silagens apresentaram valores de $\mathrm{pH}$ entre 3,89 a 4,13 . Houve aumento linear $(\mathrm{P}<0,01)$ no teor de matéria seca (MS), maior teor $(50,39 \%)$ com inclusão de $40 \%$. Houve decréscimo linear $(\mathrm{P}<0,01)$ nos teores para fibra em detergente neutro $(\mathrm{FDN})$, extrato etéreo $(\mathrm{EE})$, fibra em detergente ácido (FDA) e nitrogênio amoniacal (N-NH3). Carboidratos totais (CHOT), carboidratos não fibrosos $(\mathrm{CNF})$ e nutrientes digestíveis totais (NDT) tiveram comportamento linear crescente $(\mathrm{P}<0,01)$ com o aumento dos níveis. Recomenda-se a inclusão de $40 \%$ de resíduo de fecularia.

Palavras-chave: Ensilagem; Resíduo agroindustrial; Composição bromatológica; Estabilidade

\section{ABSTRACT}

The aim of this study was to evaluate Elephant grass ( $P$. purpureum schum) silages with the inclusion of cassava starch by-products. The design was completely randomized with five levels of inclusion of residue in the natural matter $(0 \%, 10 \%, 20 \%, 30 \%$ and $40 \%)$ with four replications. The silos were opened after 49 days of fermentation. Stability was prolonged with increasing residue levels. The addition of cassava starch by-product's reduced gas losses. The silages presented $\mathrm{pH}$ values between 3.89 and 4.13 . There was a linear increase $(\mathrm{P}<0.01)$ in dry matter $(\mathrm{DM})$, higher content $(50.39 \%)$ with inclusion of $40 \%$. There was a linear decrease $(\mathrm{P}<0.01)$ in the levels of neutral detergent fiber (NDF), ether extract $(\mathrm{EE})$, acid detergent fiber (ADF) and ammonia nitrogen (N-NH3). Total carbohydrates (CHOT), non-fibrous carbohydrates (CNF) and total digestible nutrients (NDT) had a linear increasing behavior $(\mathrm{P}<0.01)$ with increasing levels. It is recommended to include $40 \%$ of cassava starch by-product.

Keywords: Ensilage; agro-industrial by-produtcs; Bromatological composition; Stability

\footnotetext{
${ }^{1}$ SENAR

${ }^{2}$ Universidade Federal do Oeste do Pará. *E-mail: andreavinente @ gmail.com
} 


\section{INTRODUÇÃO}

A produção de forrageiras no Brasil afeta diretamente as condições nutricionais dos rebanhos, visto que nos períodos secos o crescimento e a qualidade das forrageiras ficam comprometidos (BONFÁ et al., 2015). A estacionalidade das gramíneas tropicais torna necessária a busca de alternativas que possam garantir alimento para os animais no período da seca, sendo a ensilagem uma opção de conservação de forragens, que através da fermentação anaeróbica, produz silagem e garante a oferta de alimentos em períodos escassos (EVANGELISTA et al., 2004).

Dentre as gramíneas tropicais perenes se destaca o capim elefante (Pennisetum purpureum schum) que é tradicionalmente utilizado para corte em capineiras, se destaca como forrageira para ensilagem, pois tem um excelente potencial de produção de matéria seca e valor nutritivo, com isso, uma alternativa para culturas anuais. Visando um melhor valor nutritivo, tem sido recomendado o corte desta forrageira quando nova, porém é necessário eliminar o excesso de umidade na forragem (ANDRADE; LAVEZZO, 1998; ZANINE et al., 2006).

O capim-elefante deve ser cortado com 60 dias de desenvolvimento para a produção de silagem, mas o teor de matéria seca nesta idade é muito baixo, chegando a 15 e $20 \%$, o que não seria recomendado para o processo de ensilagem, com isso, é recomendo a adição de produtos ricos em matéria seca ou por tratamentos que eliminem esse excesso de umidade da forragem (CÂNDIDO et al., 2007; CARVALHO et al., 2007; TEIXEIRA et al., 2008).

Entretanto, o capim-elefante apresenta baixas concentrações de carboidratos solúveis, alta capacidade tampão e alto teor de umidade no momento ideal de corte e esses fatores inibem os processos fermentativos adequados, dificultando os processos de silagens de boas qualidades e prejudicando a qualidade do produto conservado (MCDONALD, 1981; LAVEZZO, 1993; GUIM et al., 2002; RODRIGUES et al., 2005).

A ensilagem de gramíneas com alto teor de umidade favorece as perdas durante as diferentes fases de processo e identificar as fontes dessas perdas é muito importante para maximizar a sua utilização (BERNARDINO et al., 2005). Ao elaborar silagens a partir de forrageiras com baixo teor de matéria seca pode proporcionar o desenvolvimento de bactérias que produzem ácido butírico, assim, provocando a degradação de proteína e ácido lático (MCDONALD, 1981). Segundo esse autor com a formação de ácido lático 
butírico acaba ocasionando a perdas de matéria seca, em decorrência da produção de CO2 e $\mathrm{H} 2 \mathrm{O}$, e de energia.

Uma forma de aumentar o teor de matéria seca da silagem é a utilização de subprodutos que possam ser incorporados ao capim e melhorar a sua qualidade nutricional. Estes resíduos podem ser usados no enriquecimento de silagens como também diretamente no cocho dos animais (VALENTE, 2011).

A produção de coprodutos oriundos da mandioca é grande na região, e tal produção gera resíduos que são pouco aproveitados e que poderiam ter grande valor na nutrição animal, associados a alimentos volumosos, como na retenção de umidade e acréscimo de valor nutritivo em silagens de forrageiras, nesse contexto e pela grande disponibilidade de um potencial aditivo oriundo da indústria da fécula de mandioca na região metropolitana de Santarém-PA. Por isso, objetivou-se com o presente estudo avaliar as características fermentativas e químico-bromatológica de silagens de capim elefante (Pennisetum purpureum Schum) com a inclusão de diferentes níveis do resíduo da fecularia de mandioca.

\section{MATERIAL E MÉTODOS}

A forrageira utilizada para o experimento foi obtida do banco de Germoplasma da Fazenda Experimental da UFOPA, Km37 da PA-370, na cidade de Santarém-Pará. A Gramínea utilizada foi o Capim Elefante (P. purpureum Schum) cv. Roxo cortado com aproximadamente 120 dias após rebrota, de forma manual rente ao solo, e picado com o auxílio de uma picadeira estacionária com tamanho médio de partículas de 4,0 $\mathrm{mm}$ aproximadamente, em seguida o material picado foi pré emurchecido ao sol por $2 \mathrm{~h}$ para perda do excesso de umidade.

O resíduo de fecularia de mandioca foi obtido de uma pequena propriedade onde produziam farinha, na cidade de Santarém-PA. O material passou por desidratação natural e depois levado à estufa a $55^{\circ} \mathrm{C}$ por 72 horas, atingindo nível de matéria seca $85,3 \%$, adequado para o processo de ensilagem.

O delineamento utilizado foi inteiramente casualizado com cinco tratamentos e quatro repetições onde, T1- Tratamento sem inclusão de resíduo de fecularia, apenas capim (tratamento controle), T2- 10\% de inclusão, T3- 20\% de inclusão, T4- 30\% de inclusão, e T5- 40\% de inclusão de resíduo de fecularia de mandioca com base na matéria natural. 
A realização do experimento ocorreu no laboratório de bromatologia da Universidade Federal do Oeste do Pará (UFOPA), latitude - 2.4217811, longitude - 54.7399841, onde o material foi compactado manualmente em silos experimentais de PVC (100 mm) com altura de $30 \mathrm{~cm}$ e raio de $5 \mathrm{~cm}$, utilizando soquete de madeira, de modo a atingir a densidade de $600 \mathrm{~kg} / \mathrm{m}^{3}$ (1,650 kg de silagem em cada silo). Os silos foram dotados de válvula do tipo Bunsen para o escape dos gases com tampas comerciais de PVC a fim de evitar entrada de ar nesses microambientes.

Em seguida os silos foram pesados, vedados e armazenados. Após 49 dias de fermentação, os silos foram abertos descartando $10 \mathrm{~cm}$ iniciais onde poderia haver partes deterioradas. Foram retirados 9 gramas do material, adicionados $60 \mathrm{ml}$ de $\mathrm{H} 2 \mathrm{O}$ destilada para determinar os valores de $\mathrm{pH}$, segundo a metodologia descrita por Silva e Queiroz (2002).

A determinação das perdas totais de Matéria Seca foi calculada pela diferença entre o peso bruto de MS inicial e final dos silos, em relação a quantidade de forragem ensilada (MS). Foi descontado o peso do silo na ensilagem e na abertura, conforme equação descrita por Schmidt (2006).

$\mathrm{PMS}=[(\mathrm{MSi}-\mathrm{MSf})] \times 100 / \mathrm{MSi}$

Onde: PMS = Perda Total de MS; MSi = Quantidade de MS inicial. Peso do silo após enchimento - peso do conjunto vazio, sem a forragem, antes do enchimento (tara seca) $\mathrm{x}$ teor de MS da forragem na ensilagem;

MSf = Quantidade de MS final. Peso do silo cheio antes da abertura - peso do conjunto vazio, sem a forragem, após a abertura dos silos (tara úmida) x teor de MS da forragem na abertura.

As perdas por gases e a recuperação de matéria seca (MS) foram quantificadas de acordo com as equações propostas por Paziani et al., (2006). A determinação das perdas por gases foi calculada pela diferença de peso da massa de forragem no momento da ensilagem e da abertura e seus respectivos teores de MS (equação 1) .

$G=\frac{(P f e-P a b)}{(M F f e \times M S f e)} \times 100$

em que: $\mathrm{G}$ perda por gases (\% MS); Pfe = peso do minisilo cheio no fechamento $(\mathrm{kg})$; $\mathrm{Pab}=$ peso do minisilo cheio na abertura $(\mathrm{kg}) ; \mathrm{MFfe}=$ massa de forragem no fechamento $(\mathrm{kg}) ; \mathrm{MSfe}=$ teor de matéria seca da forragem no fechamento $(\% \mathrm{MS})$. 
O índice de recuperação de matéria seca (RMS) foi obtido através do peso obtido pela pesagem da massa de forragem nos momentos da ensilagem e da abertura e seus respectivos teores de MS (equação 2).

$$
R M S=\frac{(M F a b \times M S a b)}{(\text { MFfe } x \text { MSfe })} \times 100
$$

em que: $\mathrm{RMS}=$ índice de recuperação de matéria seca $(\%)$; MFab = massa de forragem na abertura $(\mathrm{kg}) ; \mathrm{MSab}=$ teor de matéria seca da forragem na abertura (\%); MFfe = massa de forragem no fechamento $(\mathrm{kg}) ; \mathrm{MSfe}=$ teor de matéria seca da forragem no fechamento $(\%)$.

Para o ensaio da estabilidade aeróbia foi feito uma amostra composta para cada tratamento (T1, T2, T3, T4, T5) com 2 kg de silagem não compactado acondicionadas em baldes de polipropileno com capacidade para $15 \mathrm{~kg}$, onde ficaram por 7 dias em uma sala fechada com temperatura ambiente. A temperatura da sala foi monitorada duas vezes ao dia (8:30 e 20:30 h) durante sete dias, junto com a temperatura das silagens, com uso de termômetro inserido a $10 \mathrm{~cm}$ da massa. A temperatura ambiente foi monitorada com o mesmo termômetro utilizado na temperatura das silagens. Foram avaliados 14 tempos de avaliação $(0,24,36,48,60,72,84,96,108,120,132,144,156,168$ horas após a abertura dos silos) e no mesmo horário foram aferidos também os valores de $\mathrm{pH}$, segundo a metodologia descrita por Silva e Queiroz (2002). A estabilidade aeróbia foi calculada como o tempo, em horas para que as silagens, após a abertura do silo, elevassem sua temperatura em $2^{\circ} \mathrm{C}$ acima da temperatura média ambiente $\mathrm{O}^{\prime}$ Kiely et al., (2001).

A composição químico-bromatológica, das amostras in natura e da silagem foi obtida segundo AOAC (1990) para matéria seca (MS), matéria mineral (MM), proteína bruta $(\mathrm{PB})$, extrato etéreo (EE), nitrogênio amoniacal em percentagem do nitrogênio total (N$\mathrm{NH} 3$ /N total). Fibra em detergente neutro (FDN), fibra em detergente ácido (FDA) foram determinadas de acordo com Van Soest et al., (1991). Para estimativa dos carboidratos totais (CHOT) foi usada a equação proposta por Sniffen et al., (1992): CHOT = 100 $(\% \mathrm{~PB}+\% \mathrm{EE}+\% \mathrm{MM})$. Os carboidratos não fibrosos foram calculados pela equação $\mathrm{CNF}=100-($ FDN + PB $+\mathrm{EE}+\mathrm{MM})$, conforme Mertens (1997). A determinação dos teores de nutrientes digestíveis totais (NDT) foi feita por estimativa descrita por Teixeira et al., (1998): NDT $(\%)=87,84-(0,7 * \%$ FDA $)$, em que: NDT: nutrientes digestíveis totais; FDA: fibra insolúvel em detergente ácido. 
As médias das variáveis $\mathrm{pH}$, perdas de matéria seca, perda por gases e recuperação de matéria seca foram submetidas a análise de variância utilizando o programa estatístico SISVAR 5.6 e as médias comparadas pelo teste de Tukey $5 \%$ de probabilidade.

Os resultados dos componentes químico-bromatológicos matéria seca, matéria mineral, matéria orgânica, fibra em detergente ácido, fibra em detergente neutro, extrato etéreo, proteína bruta, carboidratos não fibrosos, carboidratos totais e nutrientes digestíveis totais foram analisados através do programa computacional SAS (Statistical Analysis System). Os dados foram submetidos à análise de variância através do PROC GLM (General Linear Models), onde foram testados contrastes linear e quadrático. Foi utilizado o nível de significância de $5 \%(\mathrm{P}<0,05)$ para o teste realizado.

Tabela 1. Composição químico-bromatológica in natura dos ingredientes utilizados na produção das silagens.

\begin{tabular}{ccccccc}
\hline \multirow{2}{*}{ VARIÁVEL } & $\begin{array}{c}\text { Resíduo da } \\
\text { Fecularia de }\end{array}$ & \multicolumn{5}{c}{ Nível (\% na Matéria Natural) } \\
\cline { 5 - 7 } & Mandioca & 0 & 10 & 20 & 30 & 40 \\
\hline MS (\%) & 85,3 & 23,69 & 33,94 & 40,15 & 45,71 & 49,25 \\
MM (\%) & 1,36 & 5,27 & 3,99 & 3,57 & 2,74 & 2,42 \\
FDA (\%) & 12,3 & 42,60 & 35,01 & 29,52 & 24,46 & 18,75 \\
FDN (\%) & 22,27 & 67,12 & 50,17 & 39,67 & 32,89 & 25,80 \\
EE (\%) & 0,56 & 1,25 & 0,52 & 0,39 & 0,25 & 0,24 \\
PB (\%) & 3,13 & 6,27 & 5,23 & 4,19 & 3,40 & 3,14 \\
CNF (\%) & 72,68 & 20,09 & 40,08 & 52,17 & 60,72 & 68,68 \\
CHOT (\%) & 94,95 & 86,85 & 87,45 & 90,68 & 92,06 & 93,37 \\
NDT (\%) & 79,23 & 58,02 & 63,33 & 67,17 & 70,71 & 74,71 \\
\hline
\end{tabular}

$\mathrm{MS}=$ matéria seca; $\mathrm{MM}=$ =matéria mineral; $\mathrm{MO}=$ =matéria orgânica; $\mathrm{FDA}=$ fibra em detergente ácido; FDN=fibra em detergente neutro; $\mathrm{EE}=$ extrato etéreo; $\mathrm{PB}=$ proteína bruta; $\mathrm{CNF}=$ Carboidratos não fibrosos; $\mathrm{CHOT}=$ carboidratos totais; $\mathrm{NDT}=$ nutrientes digestíveis totais.

Fonte: Silva et al., (2021, p. 06) 


\section{RESULTADOS E DISCUSSÃO}

Os valores das médias percentuais das variáveis avaliadas, Perdas por Gases (PG), Recuperação da Matéria Seca (RMS), Perdas de Matéria Seca (PMS) e pH na abertura dos silos das silagens de capim elefante com níveis crescentes de resíduo de fecularia encontram-se na (Tabela 2). As perdas por gases e de matéria seca foram maiores nas silagens sem inclusão do resíduo de fecularia, o que representou maior recuperação de matéria seca nessas silagens com o aditivo.

Houve efeito da adição de resíduo de fecularia na silagem de capim elefante para todas as variáveis estudadas. Podendo ser concluído assim que, as condições fermentativas tiveram efeito positivo com a adição de resíduo de fecularia, esse fato deve ser atribuído à diminuição do teor de umidade do capim pelo resíduo de fecularia.

O maior resultado das Perdas por Gases foi identificado no tratamento sem adição $(0,044 \%)$ e o de menor resultado no tratamento com inclusão de $40 \%$ de resíduo de fecularia $(0,021 \%)$ onde, provavelmente essa redução das perdas por gases está associada a diminuição de microrganismos produtores de gás, como as bactérias do gênero clostridium e enterobactérias, que se manifestam em silagens de má qualidade que foram mal conservadas (PEREIRA e SANTOS, 2006).

Tabela 2. Valores médios das perdas por gases (PG), recuperação de matéria seca (RMS), e perda de matéria seca (PMS)

\begin{tabular}{cccccccc}
\hline & \multicolumn{7}{c}{ Níveis de inclusão } \\
Variáveis & T1 & T2 & T3 & T4 & T5 & P & Média \\
\cline { 2 - 6 } & 0 & $10 \%$ & $20 \%$ & $30 \%$ & $40 \%$ & & \\
\cline { 2 - 6 } PG (\%) & $0,044 \mathrm{a}$ & $0,029 \mathrm{~b}$ & $0,026 \mathrm{bc}$ & $0,024 \mathrm{bc}$ & $0,021 \mathrm{c}$ & $<0,0001$ & 0,029 \\
RMS (\%) & $78,75 \mathrm{~b}$ & $89,03^{\mathrm{a}}$ & $92,23 \mathrm{a}$ & $95,19 \mathrm{a}$ & $91,04 \mathrm{a}$ & $<0,001$ & 89,25 \\
PMS (\%) & $21,25 \mathrm{a}$ & $10,97 \mathrm{~b}$ & $7,77 \mathrm{~b}$ & $4,80 \mathrm{~b}$ & $8,96 \mathrm{~b}$ & $<0,0005$ & 10,75 \\
pH & $3,84 \mathrm{~b}$ & $3,89 \mathrm{~b}$ & $3,94 \mathrm{ab}$ & $3,82 \mathrm{~b}$ & $4,13 \mathrm{a}$ & $<0,0024$ & 3,92 \\
\hline
\end{tabular}

Médias seguidas por letras diferentes na linha diferiram entre si. T1- Tratamento sem inclusão (controle), T2- inclusão de 10\% de resíduo, T3- inclusão de 20\% de resíduo, T4- inclusão de $30 \%$ de resíduo, e T5- inclusão de $40 \%$ de resíduo de fecularia.

Fonte: Silva et al., (2021, p. 07) 
Quanto à recuperação de matéria seca constatou-se que houve diferença significativa da adição do resíduo de fecularia em relação ao tratamento sem inclusão, onde este obteve o menor valor $(78,75 \%)$, quanto aos outros tratamentos com adição do resíduo não diferiram significativamente, vale destacar que os tratamentos obtiveram uma elevação considerável e que o nível de inclusão mais baixo foi o suficiente para uma recuperação de matéria seca se igualando significativamente com os níveis de maior inclusão, atribuindo assim ao resíduo de fecularia um ótimo subproduto e mostrando que $10 \%$ de inclusão é o bastante para recuperação de matéria seca de silagens. Zanine et al., (2006) em estudo verificando o efeito do farelo de trigo sobre as perdas, recuperação da matéria seca e composição bromatológica de silagem de capim-mombaça, observou que para recuperação de matéria seca a nível considerado ideal (30\%MS) precisou da inclusão de $20 \%$ de farelo de trigo.

Com relação às perdas de matéria seca, observou se que o tratamento sem inclusão do resíduo apresentou o maior valor, e ressaltando que a porcentagem mais baixa da inclusão do resíduo de fecularia conseguiu reduzir essas perdas de Matéria seca pela metade.

Quanto ao pH das silagens, o menor valor obtido 3,82 foi do tratamento 4 com $30 \%$ de inclusão, entretanto, os maiores valores de pH observados com 20 e $40 \%$ de inclusão. Embora a variável pH não seja sinônimo de boa fermentação, no geral as silagens tiveram valores de $\mathrm{pH}$ situados na faixa ideal de uma silagem de qualidade valores entre 3,8 e 4,2. Em um estudo, Carvalho et al., (2008) observaram valores de $\mathrm{pH}$ parecidos ao adicionarem 21 e $28 \%$ de farelo de cacau na ensilagem de capim-elefante $(3,89)$, corroborando com isso, Monteiro et al., (2011) avaliando silagens de capim elefante aditivadas com farelo de arroz, casca de soja, fubá de milho e com inoculante obtiveram valores médios próximos ao obtido neste trabalho $(3,84)(3,93)(3,86)$ e $(3,96)$ respectivamente.

A estabilidade aeróbia das silagens, estabelecida como o aumento em $2^{\circ} \mathrm{C}$ da temperatura da silagem em relação a temperatura ambiente, foi observado maior valor nas silagens sem inclusão do resíduo de fecularia. A variação de temperatura de todas as silagens foi de $\left(27,7\right.$ e $\left.42,5^{\circ} \mathrm{C}\right),\left(27,7\right.$ e $\left.32,2^{\circ} \mathrm{C}\right),\left(27,9\right.$ e $\left.36,7^{\circ} \mathrm{C}\right),(27,6$ e 29,5$)$ e $(27,7$ e 29,5$)$ para os tratamentos T1, T2, T3, T4 e T5 respectivamente. O comportamento das silagens à medida que o tempo passou está apresentado na Figura 1. 
O tratamento sem inclusão de resíduo teve quebra de estabilidade com 36h após a abertura atingindo um pico de temperatura de $42,5^{\circ} \mathrm{C}$, a alta temperatura pode ser explicada pela suposta presença de leveduras, pois sua rápida propagação em variado $\mathrm{pH}$ (3 a 8), tornando-as em um dos primeiros microrganismos a surgir na aerobiose da silagem, e segundo Jobim et al., (1997) esse surgimento indesejado provoca aumento da temperatura pela liberação de calor devido ao consumo dos açucares e produção de $\mathrm{CO} 2$, causando perdas de matéria seca e o aumento da possibilidade de ocorrer reação de Maillard. A silagem com $10 \%$ de inclusão apresentou quebra de estabilidade após $48 \mathrm{~h}$, as silagens com $20 \%$ de inclusão por volta de 120 horas, silagens com inclusão de 30 e $40 \%$ não tiveram quebra de estabilidade até a última coleta de dados (168 horas). Podendo ser observado um efeito linear, a quebra da estabilidade das silagens foi adiada a medida em que aumentavam os níveis de inclusão do resíduo de fecularia a ponto de nos tratamentos com inclusão de 30 e 40\%, mesmo após se passarem 168 horas não acontecer a quebra da estabilidade.

Com isso, neste experimento, pode ser concluído que a adição de resíduo de fecularia melhorou a estabilidade aeróbia das silagens, pois as mesmas aumentaram o tempo da quebra da estabilidade em relação ao tratamento sem inclusão do resíduo, porém vale ressaltar que segundo Jobim et al., (2007), afirmam que a velocidade de degradação da silagem pela avaliação da temperatura pode apresentar baixa confiabilidade quando feita em ambientes controlados por não ser as mesmas condições encontradas a campo.

Houve variação nos valores de $\mathrm{pH}$, porém, mais acentuada nos tratamentos $\mathrm{T} 1$ e T2 e pouco nos tratamentos T4 e T5 durante o período de aerobiose da silagem (Figura 2). A elevação do pH pode ser explicada segundo Kung Jr. et al., (2003) onde o mesmo afirma que o aumento do $\mathrm{pH}$ significa um indício de degradação da silagem e dos ácidos orgânicos por bactérias e fungos causando elevação de temperatura e pH. 
Figura 1 - Variação da temperatura das silagens quando expostas a temperatura ambiente dos: T1- Tratamento sem inclusão (TRAT 1), T2- inclusão de 10\% de Resíduo (TRAT 2), T3inclusão de 20\% de resíduo (TRAT 3), T4- inclusão de30\% de resíduo (TRAT 4), e T5inclusão de 40\% de resíduo de fecularia (TRAT 5).

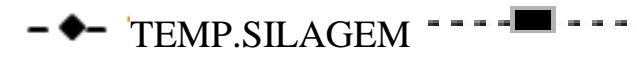

\section{TEMP.AMBIENTE}

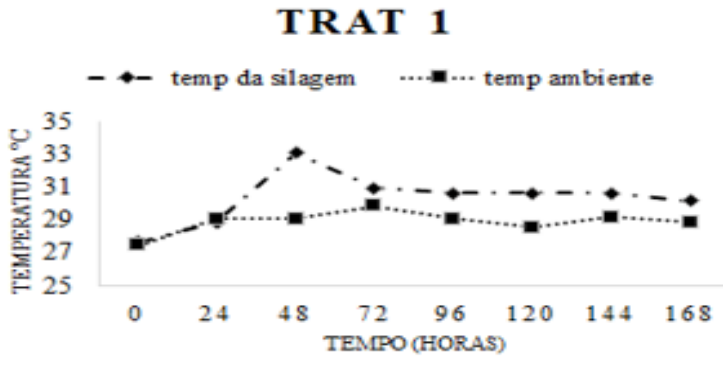

TRAT 3

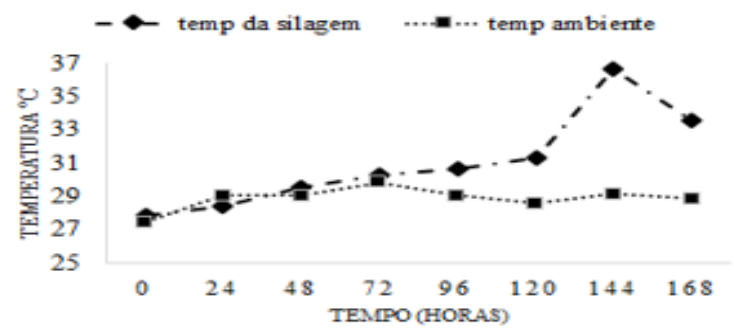

TRAT 5

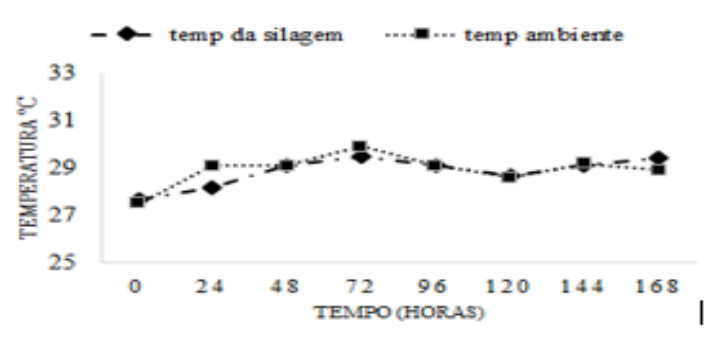

Fonte: Silva et al., (2021, p. 10)
TRAT 2

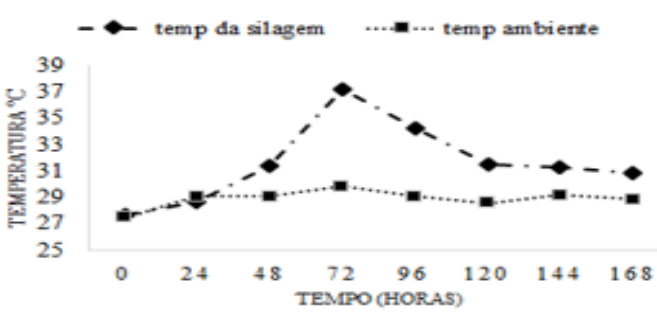

TRAT 4

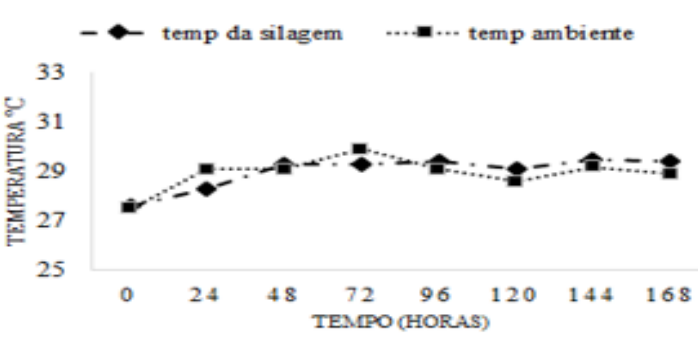


Figura 2 - Comportamento das silagens de capim elefante de acordo com o tempo em aerobiose com relação ao pH dos T1- Tratamento sem inclusão, T2- inclusão de 10\% de resíduo, T3inclusão de 20\%, T4- inclusão de 30\% de resíduo, e T5- inclusão de 40\% de resíduo de fecularia.

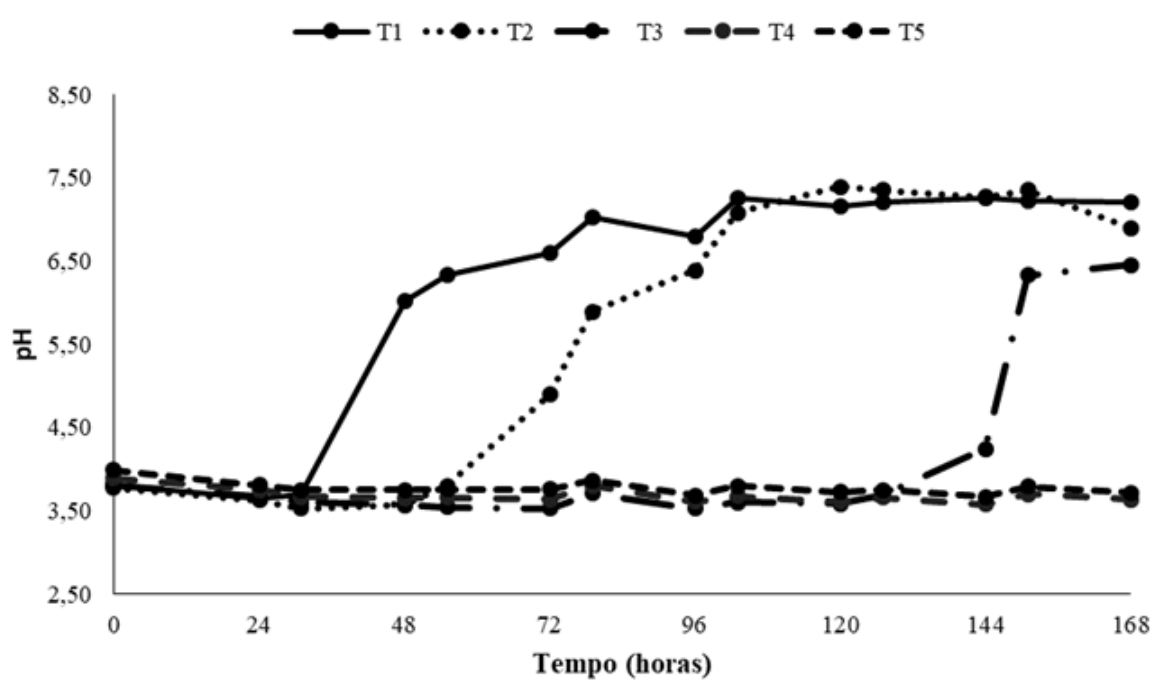

Fonte: Silva et al., (2021, p. 11)

Segundo Filya et al., (2006) silagens que ficam expostas ao ambiente podem manifestar degradação do material, com perda de nutrientes. Porém esse processo de degradação depende do material que vai ser ensilado devido seu valor nutricional e do tempo em que este vai ser exposto ao ar (CHEN E WEINBERG, 2014).

Em relação a matéria seca das silagens, houve um aumento linear $(\mathrm{P}<0,01)$ no teor com a adição do resíduo de fecularia, esse resultado já era esperado devido ao processo de secagem do resíduo que o deixou com alto teor de matéria seca $(85,3 \%)$ e com sua alta capacidade de retenção de umidade. Desse modo, foi constatado no presente estudo que o resíduo de fecularia propiciou (até mesmo com a inclusão mínima de 10\% acarretando em 31,74\%MS) o teor de MS exigido para o bom desenvolvimento de bactérias láticas na forragem a ser ensilada para obtenção de uma silagem de qualidade, pois abaixo desse nível, podem ocorrer fermentações indesejáveis causadas por bactérias do gênero Clostridium, as quais se desenvolvem nesses níveis baixos de matéria seca e de alta umidade (MCDONALD et al., 1981).

Em relação a fibra em detergente neutro, observou-se menores teores nas silagens com inclusão do resíduo de fecularia, ocorrendo uma redução linear $(\mathrm{P}<0,01)$ que pode ser 
explicada pelo baixo teor de FDN presente no resíduo de fecularia em relação ao capim elefante (Tabela 1).

Tabela 3. Composição químico-bromatológica das silagens.

\begin{tabular}{lllllllllll}
\hline \multirow{2}{*}{ Variável } & \multicolumn{1}{l}{ Nível de inclusão $(\%)$} & & & & & & \\
\cline { 2 - 5 } & 0 & 10 & 20 & 30 & 40 & EPM & $P$ & $L$ & $Q$ \\
\hline MS (\%) & 23,90 & 31,74 & 39,26 & 47,01 & 50,39 & 1,730 & $<0,01$ & $<0,01$ & $<0,19$ \\
MM (\%) & 5,55 & 4,44 & 3,26 & 2,78 & 2,52 & 0,026 & $<0,01$ & $<0,01$ & $<0,01$ \\
FDN (\%) & 65,88 & 43,56 & 31,88 & 30,59 & 22,31 & 1,330 & $<0,01$ & $<0,01$ & $<0,01$ \\
EE (\%) & 1,91 & 1,29 & 0,89 & 0,37 & 0,54 & 0,183 & $<0,01$ & $<0,01$ & $<0,04$ \\
PB (\%) & 5,68 & 6,82 & 5,17 & 4,79 & 3,57 & 0,884 & $<0,15$ & $<0,03$ & $<0,30$ \\
FDA (\%) & 42,30 & 32,47 & 23,91 & 22,32 & 19,43 & 1,410 & $<0,01$ & $<0,01$ & $<0,04$ \\
N-NH $(\%$ NT) & 0,84 & 0,75 & 0,71 & 0,71 & 0,52 & 0,035 & $<0,01$ & $<0,01$ & $<0,20$ \\
CHOT (\%) & 86,85 & 87,45 & 90,68 & 92,10 & 93,37 & 0,903 & $<0,01$ & $<0,01$ & $<0,90$ \\
CNF (\%) & 20,97 & 43,88 & 58,80 & 61,46 & 71,07 & 1,601 & $<0,01$ & $<0,01$ & $<0,01$ \\
NDT (\%) & 58,23 & 65,11 & 71,11 & 72,22 & 74,24 & 0,987 & $<0,01$ & $<0,01$ & $<0,04$ \\
\hline
\end{tabular}

MS=matéria seca; $\mathrm{MM}=$ matéria mineral; $\mathrm{FDN}=$ fibra em detergente neutro; $\mathrm{EE}=$ =xtrato etéreo;

$\mathrm{PB}=$ proteína bruta; FDA=fibra em detergente ácido; $\mathrm{N}-\mathrm{NH} 3=$ =nitrogênio amoniacal;

$\mathrm{CHOT}=$ carboidratos totais; $\mathrm{CNF}=$ carboidratos não fibrosos e NDT=nutrientes digestíveis totais. $\mathrm{P}=$ probabilidade, $\mathrm{L}=$ efeito linear, $\mathrm{Q}=$ efeito quadrático.

Fonte: Silva et al., (2021, p. 12)

Souza et al. (2003) incluindo 34,8\% de casca de café na silagem de capim elefante obtiveram porcentagem de FDN 61,74\%, valor semelhante ao encontrado nesse estudo com a silagem sem inclusão. Ferrari Júnior e Lavezzo (2001) com 12\% de inclusão de farelo de mandioca obtiveram porcentagem de FDN 60,37\% em silagens de capimelefante. Zanine et al. (2006) obtiveram porcentagem de FDN 43,71\% incluindo 30\% de farelo de trigo na silagem de capim elefante, valores semelhantes aos encontrados neste estudo com a inclusão de $10 \%$ de resíduo de fecularia de mandioca $(43,56 \%)$.

A redução dos teores de fibra em detergente neutro em dietas com elevada proporção de volumosos pode favorecer o maior consumo de matéria seca e ao mesmo tempo, a possibilidade de aumentar os níveis energéticos das rações para ruminantes (VAN SOEST, 1994; SOUZA et al. 2003). 
Houve redução linear $(\mathrm{P}<0,01)$ nos teores de extrato etéreo nas silagens de capim elefante com a inclusão do resíduo de fecularia, fato este que está relacionado ao baixo teor de EE presente no resíduo (Tabela 1).

Neste estudo os teores de EE variaram entre (1,91\% e 0,54\%), teores que se encontram dentro dos limites determinados. Segundo Jorge et al. (2008), o teor considerado crítico estabelecido de lipídios na dieta é de no máximo 6\% de EE na MS, valores superiores a esse prejudicam a degradação ruminal.

Oliveira et al. (2012) em estudo sobre os efeitos do farelo de mandioca na ensilagem de capim elefante emurchecido e não emurchecido, encontrou valores de EE (1,8\% e 1,3\%) para capim emurchecido e não emurchecido respectivamente, e $(0,46 \%)$ para farelo de mandioca, valores semelhantes ao encontrado nesse estudo $(1,91 \%$ e $0,54 \%)$ para capim elefante e resíduo de fecularia de mandioca, respectivamente.

Os teores de PB variaram entre 6,82\% e 3,7\%, não apresentando dados significativos $(\mathrm{P}<0,15)$, porém, houve comportamento linear $(\mathrm{L}<0,03)$ decrescente ao incluir o resíduo de fecularia de mandioca na silagem de capim elefante em decorrência dos baixos teores de PB nesse resíduo (Tabela 1), contudo, com exceção ao tratamento com $10 \%$ de inclusão que não gerou perdas de $\mathrm{PB}$ e apresentou o maior teor de todos os tratamentos $(6,82 \%)$. Fato que pode ser explicado devido a esse tratamento supostamente ter propiciado adequado ambiente e padrão de fermentação diminuindo perdas de nutrientes atingindo teor de matéria seca $(31,74 \%)$ dentro dos níveis ideais (28 a 35\%), o que não aconteceu com o tratamento controle que não apresentou o teor de matéria seca adequado $(23,90 \%)$ possibilitando perdas de PB.

Pinho et al. (2008) ao incluir 12\% de farelo de mandioca na matéria natural em silagens de capim elefante verificaram teores de PB de 5,9\% e 6,1\% no capim elefante sem emurchecimento e pré emurchecido respectivamente. Menegoti (2016) em estudo acrescentando coproduto do processamento industrial do tomate em silagens de capim elefante relatou teor de $5,01 \%$ ao incluir $30 \%$ do coproduto, valor semelhante ao encontrado neste estudo ao incluir $20 \%$ do resíduo de fecularia (5,17\%). Sá et al. (2007) adicionando $20 \%$ do subproduto do processamento da manga verificou $6,28 \% \mathrm{~PB}$, nesta pesquisa, a inclusão de resíduo de fecularia elevou o teor de PB de 5,68\% na silagem sem inclusão para $6,82 \%$ na silagem com inclusão de $10 \%$. 
Em relação a fibra em detergente ácido das silagens, apresentaram diminuição linear $(\mathrm{P}<0,01)$ à medida em que os níveis de inclusão de resíduo de fecularia de mandioca aumentavam, devido ao baixo teor desse nutriente em relação ao capim (Tabela 1).

Neste experimento foram encontradas porcentagens inferiores $(19,43 \%$ com $40 \%$ de resíduo de fecularia) das encontradas por Rezende et al., (2008) que verificaram 24,41\% com $28 \%$ de raspa de batata e das obtidas por Souza et al., (2003), que alcançaram porcentagem de $44,12 \%$ em silagens de capim-elefante com $34,8 \%$ de casca de café. Monteiro et al., (2011) em estudo sobre a inclusão de aditivos na silagem de capim elefante obteve $38,08 \%$ e $25,36 \%$ ao incluir $10 \%$ de farelo de arroz e $10 \%$ de farelo de milho respectivamente, valores próximos aos encontrados neste estudo 32,47\% e 23,91\% adicionando $10 \%$ e $20 \%$ de inclusão de resíduo respectivamente. Segundo Van Soest (1994) há uma correlação negativa entre os teores de FDA e degradabilidade do alimento, havendo maior degradabilidade quando o teor de FDA for baixo. Em relação a isso, a inclusão do resíduo de fecularia de mandioca em silagens de capim elefante propiciou teores baixos de FDA melhorando assim sua degradabilidade. Da mesma forma, Azevedo et al., (2020) verificaram que com a adição de moringa na ensilagem de capim-elefante houve menores teores de FDN e de FDA, e maior teor de PB quando comparada à silagem exclusiva de capim-elefante.

Quanto ao nitrogênio amoniacal foi observada perda linear $(\mathrm{P}<0,01)$ dos teores, sendo o menor valor encontrado de $0,52 \%$ para a silagem com $40 \%$ de inclusão e o maior valor $0,84 \%$ na silagem sem inclusão. Os teores baixos de $\mathrm{N}-\mathrm{NH} 3$ neste estudo podem representar redução de proteólise. McDonald (1991) observou que teores acima de 12\% de N-NH3 é indicativo de proteólise, provocando perdas de nutrientes e consequentemente uma baixa qualidade de silagem. De acordo com essas informações, os baixos níveis de $\mathrm{N}-\mathrm{NH} 3$ neste experimento indicaram adequado padrão de fermentação.

Os teores de carboidratos totais (CHOT) apresentaram incremento linear $(\mathrm{P}<0,01)$ com a adição de resíduo de fecularia, sendo o maior teor 93,37\% observado na silagem com $40 \%$ de inclusão, e o menor 86,85\% na silagem sem inclusão. Oliveira et al., (2012) relataram que os valores de carboidratos são influenciados pelos valores de PB e EE, com isso, tendo em vista que o resíduo da fecularia de mandioca apresenta baixos níveis desses nutrientes (Tabela 1), provavelmente, proporcionou resposta positiva nas inclusões do aditivo utilizado. 
Com relação aos carboidratos não fibrosos, os maiores teores de $71,07 \%$ foram observados nas silagens com $40 \%$ de inclusão, e os menores valores de carboidratos não fibrosos foram verificados nas silagens com $0 \%$ de inclusão, podendo assim ser concluído que aumentando os níveis de inclusão do resíduo de fecularia na silagem também vai aumentar o teor de carboidratos não fibrosos. Segundo NRC (2001) esses teores equivalem a aproximadamente $98 \%$ da digestibilidade do alimento, e para ruminantes esses teores variam de $32 \%$ a $42 \%$ na dieta, sendo assim, a inclusão mínima de $10 \%$ do resíduo de fecularia na silagem de capim elefante já seria suficiente para atender os teores de CNF determinados para ruminantes, tendo em vista que elevou os teores de 20,97\% a $43,88 \%$ da silagem com $0 \%$ de inclusão para a silagem com $10 \%$ de inclusão respectivamente.

Ribeiro et al., (2008) verificaram aumento linear $(\mathrm{P}<0,01)$ no teor de CNF de $(8,8 \%$; $12,3 \% ; 14,7 \% ; 15,9 \%$ e 20,5\%) da MS em silagem de capim Tanzânia com inclusão de com 0, 8, 16, 24 e 34\% de farelo de trigo, respectivamente. Bureenok et al., (2011) em estudo incluindo 5\% de melaço na silagem de capim Braquiária também observaram aumento dos níveis de carboidratos não fibrosos de 14,7 g/kg MS para 29,8 g/kg MS.

Os maiores resultados de nutrientes digestíveis totais foram observados nas silagens com $40 \%$ de inclusão do resíduo de fecularia $(74,24 \%)$ e o menor nas silagens sem inclusão $(58,23 \%)$, apresentando aumento linear em relação a inclusão do resíduo. Esses resultados já eram esperados devido a redução dos teores de FDN e FDA nas silagens e pelo resíduo de fecularia de mandioca ter possivelmente teores elevados de carboidratos solúveis.

Bergamaschine et al., (2006) com o uso de 10\% de polpa cítrica como aditivo na silagem de capim marandu, observaram aumento de 55,58\% para 59,09\% de NDT. Andrade et al., (2010) incluindo farelo de mandioca em silagens de capim elefante também verificaram aumento linear do NDT com diferentes níveis deste aditivo, corroborando com os dados encontrados neste estudo.

\section{CONCLUSÃO}

A adição do resíduo de fecularia de mandioca na ensilagem do capim elefante proporcionou melhorias quantitativas e qualitativas nas silagens com $40 \%$ de inclusão, já que apresentaram bom padrão fermentativo, sem quebra da estabilidade aeróbia, além de elevações nos teores de MS, CNF e NDT, também promoveu reduções dos componentes 
fibrosos e baixos teores de N-NH3, e por esta razão, se recomenda a utilização de $40 \%$ de inclusão.

\section{REFERÊNCIAS}

ANDRADE, I.V.O.; PIRES, A.J.V.; CARVALHO, G.G.P.; VELOSO, C.M.;

BONOMO, P. Perdas, características fermentativas e valor nutritivo da silagem de capim-elefante contendo subprodutos agrícolas. Revista Brasileira de Zootecnia, v.39, n.12, p.2578-2588, 2010.

ANDRADE, J.B.; LAVEZZO, W. Aditivos na ensilagem do capim-elefante. I. Composição bromatológica das forragens e das respectivas silagens. Pesquisa Agropecuária Brasileira, v.33, n.11, p.1859-1872, 1998.

AOAC - ASSOCIATION OF OFFICIAL ANALYTICAL CHEMISTS. Official methods of analysis. Washington: AOAC,1990.

AZEVEDO, M. M. R.; GUIMARÃES, A. K. V.; CABRAL, I. S.; BARBOSA, C. R.; MACHADO, L. S.; PAMTOJA, J. C. Características de silagens de capim-elefante (Pennisetum purpureum Schum.) com níveis de inclusão de moringa (Moringa oleífera Lam.). Braz. J. of Develop., Curitiba, v. 6, n. 9, p.71418-71433, 2020.

BERGAMASCHINE, A.F.; PASSIPIÉRI, M.; VERIANO FILHO, W.V.; ISEPON, O.J.; CORREA, L.A. Qualidade e valor nutritivo de silagens de capim marandu (B. brizantha cv. Marandu) produzidas com aditivos ou forragem emurchecida. Revista Brasileira de Zootecnia, v.35, p.1454-1462, 2006.

BERNARDINO, F. S.; GARCIA, R.; ROCHA, F. C.; SOUZA, A. L.; PEREIRA, O. G. Produção e características do efluente e composição bromatológica da silagem de capim-elefante contendo diferentes níveis de casca de café. Revista Brasileira de Zootecnia, v. 34, n. 6, p. 2185-2191, 2005.

BONFÁ, C. S. et al. Silagem de capim-elefante adicionada de casca de maracujá. Arq. Bras. Med. Vet. Zootec., v.67, n.3, p.801-808, 2015.

BUREENOK, S.; SUKSOMBAT, W.; KAWAMOTO, Y. Effects of the fermented juice of epiphytic lactic acid bacteria (FJLB) and molasses on digestibility and rumen fermentation characteristics ofruzigrass (Brachiaria ruziziensis) silages. Livestock Science, v.138, p.266-271, 2011. 
CÂNDIDO, M. J. D.; NEIVA, J. N. M.; RODRIGUEZ, N. M.; FERREIRA, A. C. H. Características fermentativas e composição química de silagens de capim-elefante contendo subproduto desidratado de maracujá. Revista Brasileira de Zootecnia, v. 36, n. 5 , p. 1489-1494, 2007.

CARVALHO, G. G. P.; GARCIA, R.; PIRES, A. J. V.; AZEVEDO, J. A. G.; FERNANDES, F. E. P.; PEREIRA, O. G. Valor nutritivo e características fermentativas de silagens de capim-elefante com adição de casca de café. Revista Brasileira de Zootecnia, v. 36, n. 6, p. 1875-1881, 2007.

CARVALHO, G. G. P.; GARCIA, R.; PIRES, A. J. V.; PEREIRA, O. G.; FERNANDES, F. E. P.; CARVALHO, B. M. A. Características fermentativas de silagens de capim-elefante emurchecido ou com adição de farelo de cacau. Arquivo Brasileiro de Medicina Veterinária e Zootecnia, v. 60, n. 1, p. 234-242, 2008.

CHEN, Y., and Z. G. WEINBERG. The effect of relocation of whole-crop wheat and corn silages on their quality. J. Dairy Sci. 97:406-410, 2014.

EVANGELISTA, A. R. et al. Produção de silagem de capim-marandu (Brachiaria brizantha Stapf cv. Marandu) com e sem emurchecimento. Ciênc. agrotec., Lavras, v. 28, n. 2, p. 443449, mar./abr., 2004.

FARIA, D. J. G.; GARCIA, R.; PEREIRA, O. G.; FONSECA, D. M.; MELLO, R.; RIGUEIRA, J. P. S. Composição químico-bromatológica da silagem de capimelefante com níveis de casca de café. Revista Brasileira de Zootecnia, v. 36, n. 2, p. 301-308, 2007.

FERRARI JR. E.; LAVEZZO, W. Qualidade da Silagem de Capim-Elefante (Pennisetum purpureum Schum.) Emurchecido ou Acrescido de Farelo de Mandioca. Rev. bras. zootec., 30(5):1424-1431, 2001.

FILYA, I., E. SUCU, and A. KARABULUT. The effects of Propionibacterium acidipropioniciand Lactobacillus plantarum, applied at ensiling, on the fermentation and aerobic stability of low dry matter corn and sorghum silages. J. Ind. Microbiol.

Biotechnol, v. 33 p.353-358, 2006. 
GUIM, A.; ANDRADE, P.; ITURRINO-SCHOCKEN, R. P.; FRANCO, G. L.; RODRIGUES, A. C.; MALHIEROS, E. B. Estabilidade aeróbica de silagens de capimelefante (Pennisetum purpureum, Schum) emurchecido e tratado com inoculante microbiano. Revista Brasileira de Zootecnia, v. 31, n. 6, p. 2176-2185, 2002.

JOBIM, C. C.; NUSSIO, L. G.; REIS, R. A.; SCHMIDT, P. Avanços metodológicos na avaliação da qualidade da forragem conservada. Revista Brasileira de Zootecnia, v. 36, p. 101-119, 2007.

JOBIM, C.C.; REIS, R.A.; RODRIGUES, L.R.A.; SCHOCKEN-ITURRINO, R. P. Presença de microrganismos nas silagens de grãos úmidos de milho ensilados com diferentes proporções de sabugo. Pesq. Agropec. Bras. v.32, n.2, p.201-2014, Fev. 1997.

JORGE, J. R. V.; ZEOULA, L. M.; PRADO, I. N.; SILVA, R. R.; ANDRADE, R. V.; PRADO, J. M.; BUBLITZ, E. E. Lipídios em dietas para novilhos holandeses: 20 digestibilidade aparente. Revista Brasileira de Saúde e Produção Animal, Salvador, v.9, n.4, p. 743-753, 2008.

KUNG JR., L.; STOKES, M. R.; LIN, C. J. Silage additives. In: BUXTON, D. R.; MUCK, R. E.; HARRISON, J.H. (Eds.) Silage science and technology. Wisconsin: ASA; CSSA; SSSA. 2003.

LAVEZZO, W. Ensilagem do capim-elefante. In: SIMPÓSIO SOBRE MANEJO DA PASTAGEM, 10, 1993, Piracicaba. Anais[...] Piracicaba: Fundação de Estudos Agrários “Luis de Queiroz", 1993.p.169-276.

McDONALD, P. The biochemistry of silage. New York: John Wiley \& Sons.1981.

McDONALD, P.; HENDERSON, A.R.; HERON, S.J.E. The biochemistry of silage. 2.ed. Marlow: Chalcombe, 1991.

MENEGOTI, J. P. Valor nutritivo da silagem de capim elefante enriquecida com coproduto do processamento industrial do tomate / João Paulo Menegoti. -Descalvado, 2016. 
MERTENS D.R. Creating a System for Meeting the Fiber Requirements of Dairy Cows. Journal of Dairy Science, v.80, n.7, p.1463-1481, 1997.

MEYER, H.; BRONSCH, K.; LIEBETSEDER, J. Supplemente zu Vorlesungen und bungen inder Tierernhrung. Verlag M. e H. Schaper, Hannover, 1989.

MONTEIRO I. J. G.; ABREU J. G. A.; CABRAL L. S.; RIBEIRO M. D.; REIS R. H. P. Silagem de capim-elefante aditivada com produtos alternativos. Acta Scientiarum. Animal Sciences. Maringá, v. 33, n. 4, p. 347-352, 2011.

MUCK, R.E. Factors influencing silage quality and their implications for management. Journal of Dairy Science, v.71, n.11, p.2992-3002, 1988.

NATIONAL RESEARCH COUNCIL - NRC. Nutrient Requirements of Dairy Cattle. 7th ver. Ed. Natl. Acad. Sci., Washington, DC. 2001.

O’KIELY, P. O.; CLANCY, M.; DOYLE, E.M. Aerobic stability of grass silage mixed with a range of concentrate feedstuffs at feed-out. In: INTERNATIONAL GRASSLAND CONGRESS, 19, São Pedro. Anais[...] Piracicaba: FEALQ, 2001. p.794-795.

OLIVEIRA A. C.; GARCIA R.; PIRES A. J. V.; OLIVEIRA H. C.; ALMEIDA V. V. S.; VELOSO C. M.; ROCHA N. A. L.; OLIVEIRA U. L. C. Farelo de mandioca na ensilagem de capim-elefante: fracionamento decarboidratos e proteínas e características fermentativas. Revista Brasileira de Saúde e Produção Animal, v.13, n.4, p.10201031, 2012.

PAZIANI, S. F.; NUSSIO, L. G.; LOURES, D. R. S.; IGARASI, M. S.; PEDROSO, A. F.; MARI, L. J. Influência do teor de matéria seca e do inoculante bacteriano nas características físicas e químicas da silagem de capim Tanzânia. Acta Scientiarum. Animal Science, v. 28, n. 3, p. 265-271, 2006.

PEREIRA, O.G.; SANTOS, E.M. Microbiologia e o processo de fermentação em silagens. In: SIMPÓSIO SOBRE MANEJO ESTRATÉGICO DA PASTAGEM, 3. 2006, Viçosa, MG. Anais[...] Viçosa, MG: UFV, 2006. p.393-430. 
PINHO, B. D.; PIRES A. J. V.; RIBEIRO L. S. O.; CARVALHO G. G. P. Ensilagem de capimelefante com farelo de mandioca. Revista Brasileira de Saúde e Produção Animal., v.9, n.4, p. 641-651, 2008.

PIRES, A. J. V.; CARVALHO, G. G. P.; GARCIA, R.; CARVALHO JUNIOR, J. N.; RIBEIRO, L. S. O.; CHAGAS, D. M. T. Capim-elefante ensilado com casca de café, farelo de cacau ou farelo de mandioca. Revista Brasileira de Zootecnia, v. 38, n. 1, p. 34-39, 2009.

REZENDE, A. V.; RODRIGUES, R.; BARCELOS, A. F.; CASALI, A. O.; VALERIANO, A. R.; MEDEIROS, L. T. Qualidade bromatológica das silagens de capim-elefante aditivadas com raspa de batata. Ciência e Agrotecnologia, v. 32, n. 2, p. 604-610, 2008.

RIBEIRO, R.D.X.; OLIVEIRA, R.L.; BAGALDO, A.R.; FARIA, E.F.S.; GARCEZ NETO, A.F.; SILVA, T.M.; BORJA, M.S.; CARDOSO NETO, B.M. Capim tanzânia ensilado com níveis de farelo de trigo. Revista Brasileira de Saúde e Produção Animal, v.9, p.631-640, 2008.

RODRIGUES, P. H. M.; BORGATTI, L. M. O.; GOMES, R. W.; PASSINI, R.; MEYER, P. M. Adição de níveis crescentes de polpa cítrica sobre a qualidade fermentativa e o valor nutritivo da silagem de capim elefante. Revista Brasileira de Zootecnia, v. 34, n. 4, p. 1138-1145, 2005.

SÁ C. R. L.; NEIVA J. N. M.; GONÇALVES J. S.; CAVALCANTE M. A. B.; LÔBO R. N. B. Composição bromatológica e características fermentativas de silagens de capim elefante (Pennisetum purpureum Schum.) com níveis crescentes de adição do subproduto da Manga (Mangifera indica L.). Revista Ciência Agronômica, v.38, n.2, p.199-203, 2007.

SCHMIDT, D. C. Model-driven engineering. COMPUTER-IEEE COMPUTER SOCIETY-, v. 39, n. 2, p. 25, 2006.

SILVA, D.J.; QUEIROZ. A.C. Análise de alimentos (Métodos químicos e biológicos). 2.ed., Viçosa, MG: Universidade Federal de Viçosa, 2002. 
SNIFFEN C.J.; O’CONNOR J.D.; VAN SOEST P.J.; FOX D.G.; RUSSELL J.B. A net carbohydrate and protein system for evaluating cattle diets: II. Carbohydrate and protein availability. Journal of Animal Science. v.70, p. 3562-3577, 1992.

SOUZA, A.L.; BERNADINO, F.S.; GARCIA, R. et al. Valor nutritivo de silagem de capim-elefante (Pennisetum purpureum Shum) com diferentes níveis de casca de café. Revista Brasileira de Zootecnia, v.32, n.4, p.828-833, 2003.

TEIXEIRA, F. A.; VELOSO, C. M.; PIRES, A. J. V.; SILVA, F. F.; NASCIMENTO, P. V. N. Perdas na ensilagem de capim-elefante aditivado com farelo de cacau e canade-açúcar. Arquivo Brasileiro de Medicina Veterinária e Zootecnia, v. 60, n. 1, p. 227-233, 2008.

TEIXEIRA, J. C; TEIXEIRA LÚCIA DE F. A. C. Do alimento ao leite: entenda a função ruminal. Lavras: Universidade Federal de Lavras, 1998.

VALENTE, T. N. P. Utilização de resíduos de frutas na alimentação de ruminantes. PUBVET, Londrina, V. 5, N. 15, Ed. 162, Art. 1099, 2011.

VAN SOEST, P.J. Nutritional ecology of the ruminants. 2.ed. Ithaca: Cornell University Press, 1994. 476p

VAN SOEST, P.J.; MASON, V.C. The influence of Mallard reaction upon the nutritive value of fibrous feeds. Animal Feed Science and Technology, v.32, n.1/3, p.45-53, 1991.

ZANINE, A. M.; SANTOS, E. M.; FERREIRA, D. J.; OLIVEIRA, J. S.; ALMEIDA, J. C. C.; PEREIRA, O. G. Avaliação da silagem de capim-elefante com adição de farelo de trigo. Archivos de Zootecnia, v. 55, n. 209, p. 75-84, 2006. 